\title{
PRESIDENT'S ADDRESS DELIVERED BEFORE THE PACIFIC COAST SOCIETY OF ORTHODONTISTS, FEB. 12, 1917
}

\author{
By James David McCoy, D.D.S., Los Angeres, Calif.
}

$\mathrm{T}^{\mathrm{H}}$

$\mathrm{HE}$ time has arrived when we, as a body, must meet and discharge the duties and obligations incident to our annual meeting. As we enter upon our deliberations, we should not be unmindful of the responsibility entailed to ourselves, and to the special vocation we represent here upon this Coast, for a gathering such as this cannot but afford ample opportunities for increasing our capacity to better fulfill the obligations imposed upon us, in pursuing the arduous and exacting task of orthodontic practice.

The Purpose of the Society. - The purpose of this Society is the promotion of knowledge in all that pertains to orthodontia and its advancement as a distinct specialty, as well as to bring about fraternal and professional association of orthodontists, that through their cordial relationship, they may prove a help to one another.

Our aims will fall short of accomplishment, unless at all times we remain a thoroughly organized, efficient body, willing to work in harmony for the realization of our purpose, unhampered by professional jealousy, personal aggrandizement, and narrow prejudices.

The future will undoubtedly present many problems and responsibilities to us as an organization, and these we must successfully meet, if we are to retain our position as one of the chief factors for the progress of orthodontia on the Pacific Coast.

Restriction of Membership.-According to our constitution and by-laws, the membership in this Society is restricted to those who have received special training in the principles and practice of orthodontia; and furthermore, such members must be engaged in the exclusive and ethical practice of orthodontia. To some, such requirements seem far too strict, as they so greatly limit our membership at the present time. On the other hand, I feel that the accomplishments of our Society will be far greater and the resultant benefit to our specialty more telling through a smaller organization composed of mer vhose training and activities better equip them to cope with the problems wah which we are so deeply concerned.

I trust we will not be misunderstood if we maintain this attitude as a Society, and that no one will be led to believe that we wish to establish an aristocracy in orthodontia, but rather, an academy which shall, as the years go by, become more and more a helpful factor for the advancement of our special, vocation.

We are fortunate, indeed, to be engaged in the practice of orthodontia at a time when so many cobwebs of empiricism have been cleared from the structure of our specialty. Young as it is, its progress has been justly rated with the most advanced in the sphere of dentistry. The fact that the benefits of orthodontic treatment are fast becoming matters of common knowledge among the better 
educated members of the laity, has resulted in a much more wholesome appreciation of the orthodontist, and a decidedly increased demand for his services.

This gratifying situation offers a decided contrast to the condition existing ten or fifteen years ago, when the demands for orthodontic services were so much less universal, and the appreciation of such services proportionately small.

The Practice of Orthodontia by Those Poorly Equipped.--The popularity of orthoclontia has led many dentists who are only partially equipped to render such services, to attempt to add this branch to their practice. While this situation has its unfortunate side, it has doubtless been responsible for the dental profession coming to a more realizing sense of the demands placed upon the orthodontist, and has contributed in no small way to a keener appreciation of the real orthodontist by the profession at large.

On the other hand, it has given rise to a deplorable state of affairs, with which one is easily impressed upon a perusal of the advertising pages of some of our journals, and noting there the advertisements of dental laboratories and dental manufacturers who claim to not only make orthodontic appliances, but to furnish instructions for their use, so that the dentist wishing to handle such cases, may do so successfully (?) with their aicl. Of course, the dentist who attempts orthodontic precedures under these conditions, displays an excessive amount of ignorance, and lack of appreciation of the demands of orthodontia, when he is willing to accept as a consultant, the mechanic whose knowledge of the subject, at best, is most superficial.

Dental supply men are also often called upon to furnish appliances which will correct certain cases of malocclusion. It is no wonder, then, that we hear of failures under such circumstances, for we all realize that when practiced even under the most advantageous circumstances, orthodontic procedures are often beset with pitfalls and discouragements.

It is to be hoped the time will come when the pubishers of our various journals will come to a realizing sense of their responsibility in publishing such misleading advertisements as those referred to, for such advertisements belittle the science of orthodontia, and detract from the dignity of the journal which carries them.

It is a lamentable fact that many dentists who consicler more or less seriously the question of perfecting their knowledge along orthodontic lines, seem to feel that the demands of orthodontia are, for the most part, met with upon acquiring the working knowledge of physics and dynamics of corrective appliances.

The Importance of Etiology.-As a rule, those who regard orthodontic treatment in the light of a purely mechanical procedure are all too apt to relegate the question of etiology to a position of secondary importance, their idea being that the correction of all local conditions which make possible along normal lines, mechanics of occlusion and respiration, etc., constitutes safety in treatment.

However, to the thoughtful and scientific orthodontist, the fallacy of this attitude is very apparent, owing to the fact in a certain percentage of cases, even where the most careful treatment and retention have been carried out, failure in some degrees ensues, leading us to the conclusion that there is yet a vast amount of information to be gathered concerning the etiology of malocclusion. 
Dr. Angle has stated: "The causes of malocclusion to be intelligently comprehended, must be studied from the basis of the normal growth of the denture and its correlated parts. Most of the immediate causes are mechanical, yet whatever acts as a hindrance to nature, in performing her delicate offices in the unfolding of the various tissues composing the dental apparatus, hindering its growth, will be operative as a cause in producing malocclusion.".

While almost everyone appreciates the mechanical causes, I think I am safe in stating that comparatively few appreciate the causes that lie deeper, and which "act as a hindrance to nature performing her delicate offices," which naturally leads us to the conclusion that the orthodontist, in justice to himself and his patients, should be as thoroughly schooled in the basic principles of physiology and pathology as any other surgeon who devotes his energy to the field of orthopedics, or who aims to direct development along normal lines.

Constitutional Disorders as a Factor.-In considering constitutional disorders as a factor, it is but natural to seek out those which are active in interferring with the progress of development in the dental apparatus, and which are injurious to the tissues which enter into the formation of the structures concerned.

As we reflect upon this point, we are impressed with the fact that in the dental apparatus, as we consider it, we have all the principal tissues which are found in the other parts of the skeleton, namely, epithelium, the connecting tissues, muscular, and nervous tissues. Therefore, we have no reason to assume that these tissues, as they are associated in the dental apparatus, are any less subject to the effect of constitutional disturbances than they are in other parts of the body.

Therefore, as emphasized before, until physiology and pathology become more of an open book to us than they are now, we will be at a loss to account for certain arrestments of development, occurring not only in our field of endeavor, but also in the human organism as a whole.

There is enough evidence, however, to lead us to think that certain diseases have an important bearing upon development, or more properly speaking, upon arrestments of development occurring in the oral structures. These conditions I will enumerate briefly as follows:

1. The ordinary diseases of childhood, which are accompanied with high temperature.

2. Congenital or hereditary syphilis.

3. Rickets.

4. Diseases of the internal secretory organs.

I will make no attempt to discuss the various phases of these subjects, for that has already been done at previous meetings of this Society, but would urge a more consistent observation of these conditions, as we uncover them in taking the histories of our cases, so that we can realize in a more definite way; their significance.

The last cause mentioned, namely, diseases of the internal secretory organs, brings to our minds a field which is, as yet, imperfectly explored, although we know that the internal secretory organs have a definite relationship to bodily 
development and nutrition. We know that these glands, the principal of which are the pituitary, the adrenals, the thyroid, the parathyroids, the thymus, the testes, and the ovaries, are supposed to preside by virtue of their secretions, or in some cryptic manner, over certain correlations of the body.

"It has been claimed for these tissues and glands, that they are cooperative with, or compensate and inhibit, each other in cycle, and that any interfering influence or disease which disturbs this coordination, seriously and very diversely affects nutrition, bodily development and functions."'1 Just how great a factor these organs are in the etiology of malocclusion is a matter which physiologists will have to aid us in settling, but the importance of these structures is not to be underestimated, nor should we lose sight of them in our investigations.

Before leaving the subject of etiology, I would emphasize a point made by one of our confreres" that "the process involved in the establishment of malocclusion may be said to begin with the differentiation of the cells destined to become the future dental organs, and end with the completed, permanent dentition. If these are accepted as the two extremes of the period during which malocclusal conditions may arise, it is evident that there is a vast range of circumstances that must be taken cognizance of, if a careful examination into the causative factors of this disturbance be undertaken."

Fixed Versus Removable Appliances.-In reviewing the progress in methods of treatment during the last few years, it is interesting to note that fixed appliances have in no way lost prestige, and in fact, are now recognized almost universally by scientific orthodontists as the most rational and effective in our work.

So thoroughly has this been proved, that we hear little controversy or argument from thosc who, for a time, were loud in their claims for removable appliances. The old saying that the proof of the pudding is in the eating applies with significance in this connection, for it has been proved that through the proper use of fixed appliances, results can be obtained with a uniform degree of accuracy.

We all realize the great importance of being able to keep the force being applied to moving teeth under absolute control at all times. If an appliance can not be so constructed that we can maintain this control, it at once becomes a dangerous agent, rclativcly spcaking.

Recent developments in orthodontic appliances make it possible for us to have more accurate control over applied force than we have ever had before, as well as making possible the application to the teeth to be moved, a degree of force which, in character, is best suited to effect the physiological changes so much desired.

Metals Used for Appliances.--"The materials used for the construction of fixed appliances have as much to do with the principle of fixation, as any other factor. For example, an appliance constructed of the noble metals will not disintegrate, its temper will always remain even, though attachments be soldered to it, and its integrity will never be impaired by use in the mouth."3

On the other hand, an appliance constructed of base metals disintegrates to

${ }^{1}$ Grieves, Clarence J.: Am. Soc. of Orthodontists, 14th annual meeting.

'Hellman, Milo: Dental Cosmos, Sept., 1914.

${ }^{3}$ Casto, Frank M.: Jour. National Dental Assn., Jan., 1917. 
a certain degree in the mouth, loses its temper through soldered attachments, and thereby its usefulness is often seriously impaired.

For this reason, I feel that the use of base metals as orthodontic appliances is contraindicated, notwithstanding the fact that such appliances are highly advertised, and by some few are defended with vigor.

In the opinion of your essayist, the only quality for which the base metal appliances can be recommended is for their cheapness, and often this fails to be an argument in their favor, as they require more time and trouble in manipulation.

It has been claimed by the exponents of base metal appliances that teeth banded with these materials are less apt to disintegrate than if banded with gold, platinum, or its alloys. It seems, to me that such a claim will not stand the test of rigid investigation. Notwithstanding the fact that disintegrations do occur once in a while upon teeth carrying bands, a careful scrutiny of such cases will usually reveal the fact that this unfortunate condition was the result of either poorly constructed or poorly cemented bands, which made possible the lodgment of debris or the formation of plaques against the enamel surface, and was not due to the material composing the appliance.

In my remarks thus far, I have touched upon numerous subjects which appea] to me as important not only to us as a Society, but to orthodontia. In your consideration of my ideas upon the subject, I trust your discussion will be marked with that degree of candor which should exist between men brought together by the bond of a common purpose.

Perhaps, in our meeting, we will not bring out anything which is startlingly new or original, but we are certain, through our discussions and through our interchange of ideas, to be able to carry away much which will not only increase our capacity for better fulfilling our professional obligations, but will instill. within us renewed courage and enthusiasm.

\section{DISCUSSION}

Dr. Cavanagh--Mr. President, Fellow Members of our Society, and Guests: I trust in consideration of the fact that this paper has been excellently and carefully prepared, you will expect but little of the one who is to open the discussion, especially since I have had no opportunity whatever of knowing the lines along which our President was going to speak. He touches first on the question of membership in this Society,--whether or not we shall admit those who are not following this work exclusively. We, who have taken special instruction in orthodontia, are in a much better position to realize the vast difference between the general practitioner who dabbles in some orthodontia, and those who are really qualified for practice, both by training and years of valuable experience. For myself, I feel if we admit those who are unprepared:(not having taken a course) we have no way of limiting any man who performs any operations in orthodontia, regardless of whether he regards it as merely a mechanical procedure or not. We will have no way of excluding any of those who are endeavering to ferform orthodontic work, and if such be admitted, our Society would become unwieldy. Therefore, I think our membership should be limited in the future as it has been in the past. In order to do justice to the other points which the President mentioned, I would have needed the paper for perhaps many hours, and I might not have done so even then. We have, however, I think been postponing the treatment of cases until too late in life. Perhaps it was not our fault, inasmuch as our work is largery referred work. In orthopedic surgery, operations are not postponed until the child is ten, eleven, twelve or fifteen years of age. In the dental profession, unfortunately, many members advise the postponement of corrective measures until beyond the age when it is possible to obtain the best results with the least effort, inconvenience, and expense to the patient. All this shows that we still have important educational work to do. 
I am quite a believer in the theories of Dr. Bogue, of New York City. In the articles published in the Dental Digest, I think some excellent points are being brought out. This Journal reaches more of the dentists than our publications do. Dr. Bogue recommends patients for treatment at a much earlier age than is ordinarily done. Several years azo I went over the cases I had had up to that time, and found the average age of patients referred to me on my return from the East after taking the course was twelve years. This was out of the first fifty cases. I find up to a year ago, averaging up the cases referred, the age had been reduced to nine years, and from the proportion of cases where only the deciduous teeth are present (in those cases I have on hand at this time) I think that age has been reduced to approximately seven years as an average age. That has been the restlt of my effort,- to reduce the age at which patients are referred to me for treatment.

There is very little more that I can touch upon at this time, although it deserves a vast amount of discussion. The fact that $I$ did not have the privilege of going over the paper prior to coming here, will make my part of the discussion necessarily brief. I therefore will leave it in the hands of the other members present for further discussion.

Dr. Suggett.-Mr. President, l enjoyed the paper very much. For a number of years I have heen much interested in the matter of the proper selection of appliances, and for some time have been using only the noble metals. It seems to me the objections urged to the use of these metals are practically the same objections which may be urged with reference to gold fillings and crowns. Some dentists think they see damage from the bands,-a damage which is exerted on teeth adjacent to those which are banded. If that is true, the same object on would apply to gold crowns and fillings, or any use of gold or precions metals that would touch another tooth.

As to the appliances, it seems to me from my own experience and from that of others. the tendency is drifting not only toward the direct attachments, but I think toward a smaller wire. For a year past I have not put on a wire larger than the .0225 . That seemed small at first, but 1 know several years ago when 1 saw Dr. Young give a clinic with .030 wire, it seemed too small. But since then we have changed our method quite radically. Instead of using an attachment only from molar to molar, with ligatures, etc., we are now attaching to every tooth, or every other tooth and getting an attachment at every half inch instead of two or four inches. Since using the .0225 wire, I have found I can secure much better control and more rapidity of movement than with the .030 wire, for the reason that it is so flexible and is easier to manage and one can give a bigger spread to it than the .030 wire. Where you have an attachment, say to central or lateral incisors, you have such a small distance between the teeth that with the .030 wire your spread must be very, very small. With the .0025 wire, the spread can be much greater, and you can often let a case go much longer with it. It is simpler in making and there is no need of mechanical appliances for soldering. This eliminates the buccal tube, the middle section, and end sections,-so that this is a s.mpler appliance to use. I think there is no need to use pins that were furnished before at forty cents a pin. The .0225 wire is the same size as the pin we want to use, and you have the same rigdity you have in the wire.

The only objection I have found, is sometimes encountered with upper molars which are in lingual occlusion. I have found it difficult to jump the overbite. When this difficulty is encountered, I work with the case until about finished, leaving the molars still in lingual occlusion. Then with a short period of treatment with the buccal tube and 16 or 18 gauge wire, I move the molar teeth over and line them up quickly.

I think the tendency is toward the use of a smaller wire. Dr. Angle shows that tendency in his last appliance, and I think the profession is convinced that tooth movement does not require a great force but a constant one. In closing up a large space where a molar or bicuspid is missing, the smaller wire works better. We can get the loop with a spread that would work for two or three months safely and without any additional pressure being put on. The larger the wire, the less the change we can make each time.

The paper has touched on some of the deep causes back of some of these cases. These are the things that puzzle us. Two cases may be very similar in many respects: one may have the tendency to return for years and years, and the other to stay in its new position. So we feel there are many things we do not know yet, and so we are pursuing the subject with more and more open minds, and are willing to be taught. The dental profession feels we are not as dogmatic as we were a few years ago. We realize there is much to be learned by experience and from each other.

Dr. Engstrom.-The President's address was of considerable interest to me and a 
number of factors were touched upon which I have thought about for some time past particularly etiology and the retention of cases.

In regard to the organization of the Pacific Coast Society of Orthodontists. I atn heartily in accord with the essayist in the desire that the membership be confined to those who practice orthodontia exclusively. No doubt the Society would become unwieldy, as Dr. Cavanagh stated, if a different course were followed. We have in our by-laws a section which states that every member shall take part in the procecdings of ach session This brings us closer together, and thus a great deal more good may he accomplished.

In regard to the etiology of malocclusions, undoubtedly it is very true there are many causes which are very much in the dark, as it were. Aside from the idea that malocclusions may begin at any time from the first operation of the cell to the completion of the dental arch, or later, it appears to me that if malocclusions may be acquired at al later period in life and corrected, that should a condition exist prior to birth. that condition may be rectified and not stand against the case as a hereditary element, as it wert.

In our own work we may have two cases practically the same, but the result in one will be much more satisfactory than in the other. So it seems to me, there is a cause not to be accredited to the operator entirely, but which lies within the patient himself. If a disease attacks the body, we naturally have to depend upon the resistance of the body to overcome the disease, whatever methods may be pursted in the curc, and that resistance is in the patient. We cannot make it. And so in the correction of conditions of malocclusion, we must depend to a considerable extent on the ability of the patient to follow instructions and to do for himself that which would bring ahout a correction of the abnormal functions that existed prior to the treatment. That appears in some instances to be largely a matter of the mind and $I$ have always considered the mind to he an influence in the formation of malocclusions and also in the correction of them. A person may use a part as he desires, and thus develop it properly or not. This may apply with reference to the use of the nose. Quite often the mouth is used for the nose. Under such conditions we are bound to have an abnormal structure so far as the mouth is concerned. Now, if the patient will not correct the habit by mental effort, the success of our work is practically nil, because the abnormal function that existed before the correction, surely will tend to bring abont a return to the malocclusion. I thank you.

Jr. Martin Dewey.-...Mr. Chairman and Members: There are a great many things in the President's address I could discuss and many things on which I could disagree with him, but I will not take that liberty to a very great extent. is to noble and base metals, I think he has referred to me, as I have advocated hase metals. Several years ago we had a discussion in Chicago on this matter, and $I$ was practically alone in advocating base metals. That certain metals possess certain properties you admit. Platinum has certain properties, and we would like to use something in its place. but we cannot find a substitnte in the commercial world. Iridio-platinum has certain qualities making it desirable for use in regulating appliances, but it has no antiseptic properties. I agree with Dr. McCoy, to a certain extent, that a band properly fitted would not decay the tooth, yet some of the men in the East have said it was possible to have a gold band fitted so close to a tooth that you would exclude every bit of cement from between the band and the tooth. The value of the cement is evidently not understood for you can take a band off a tooth under careful conditions, remove a piece of cement from the band and get a heautiful culture of micronganisms. Cement does not possess as many antiseptic properties as we formerly believed. Now you can carry the experiment further, as has been done. In the mouth of the same patient you can have iridio-platinum bands and bands of base metal alloy. You can make cultures from the two bands using two different test tubes. The culture from the iridio-platinum band will contain twice as many mircroorganisms as those from the other band.

It is a fact, as Dr. Suggett has suggested, we need only to think of gold fillings and gold crowns. To doubt these do decay teeth. Self-cleansing fillings, etc, are necessary. We try to provide for mechanical cleansing,-- to avoid the accumulation of debris between the teeth. We have to consider that the banded tooth has a certain danger to the approximating tooth. With noble metal touching a tooth, that tooth is always liable to decay. Many men are realizing this. How they will meet this situation we do not know. We know iridio-platinum has certain properties which make its use necessary in certain instances, but we should use a metal containing some proportion of copper and zinc. Metallurgists are working on it.

We need to realize that where noble metals are nsed, more scrupulous care nust be taken than is employed by the average orthodontist. 
Dr. Ketcham.-In speaking of noble metals causing decay of the teeth as Dr. Dewey cxpressed it, I wonder whether the percentage of decayed teeth where we have the noble metals in use, is any greater than in the mouths where no noble metals are used. For instance, in a mouth where amalgam fillings are used, it seems to me instead of a chemical or metallurgical problem, the decay of adjoining teeth is more a question of environment and prophylaxis, and it could be taken care of by cleanliness. I believe the endeavor of some of our operators to so shape their restorations as to make them self-cleansing, is simply an effort to reproduce the anatomical structure of the tooth the same as though the tooth had not decayed, and that in reality in our orthodontic appliances the question of decay is primarily one of prophylaxis. In other words, is the likelihood of decay where precious metals are used and where alloys containing a greater percentage of copper and zinc are used, very much greater in the one case than the other? The edge of an iridio-platinum band may be raised a bit,---the cement washes out and we have decay. When a Germansilver band is used, we may have more stretch, and the same is true of some of the gold alloys, coin gold, for instance. It is a question whether scientifically the use of gold and platinum in juxtaposition to a tooth will render decay greater or not.

Dr. Solley.-I am sorry I was not here to hear the President's address, as it would have been of great interest to me. Three years ago I brought a subject before this Society and have been doing considerable experimenting on it since then, and I have had the idea that I was probably the only man having trouble along this line. I dropped the subject and am sorry I did. At that time I had one particular patient where I had been using platinum appliances and had much disintegration and had to do something and so I turned around and used certain base metal appliances. With the use of these latter appliances I had fully $85 \%$ improvement, I think, so far as disintegration of tooth structure is concerned, in that particular mouth. It was a very serious case, and I felt it was the only way I could have carried the case on. I saw the patient six months ago and I still have that particular retaining appliance on.

I wish to ask Dr. Dewey a question as to cements and cultures. Has he tried any of these new copper cements which are on the market? Is there any improvement from the standpoint of disintegration in the use of these copper cements?

Dr. Dewey.-Copper cement has a decided antiseptic property, and I should have qualified my statement as to cements. Cements containing $3 \%$ copper, have little antiseptic properties. Copper cement containing a greater percentage of copper has much greater antiseptic value.

With reference to Dr. Ketcham's remarks as to iridio-platinum, and gold and platinum, and the liability of tooth decay, I think scientific findings are what we want. Iridio-platinum and gold have no antiseptic properties. The other metals mentioned do have. You can prove the question in regard to these metals by making an experiment on agar-agar plates. Take the iridio-platinum and the gold and platinum and the microorganisms crawl up over the metal. While around metal containing copper or zinc you will find a clear space. The microorganisms have died.

I could cite you a number of men, prominent in the orthodontic world, who are discontinuing the use of iridio-platinum and gold and platinum. A large portion of the cases of decay in many mouths can be traced to the use of noble metals. It is a fact and not an imaginary proposition. The experience of Dr. Solley has been the experience of a number of men, and while we must use noble metals, we must not deceive ourselves, because a band keeps clean, into a belief that it may not cause decay of a tooth. A thing may be perfectly clean macroscopically, and still be covered with microorganisms. This decays a tooth, and not the oxidation of your appliances.

Dr. Hampton.-I am just a visitor here and I appreciate the kindness extended to me, and I have enjoyed the President's address very much. I am in general practice. I noted Dr. Dewey's statements with reference to tooth decay occurring adjacent to a gold filling and his remarks with reference to zinc and copper. Is it a question as to whether the galvanic action destroys the microorganisms, where you do not have that action in the s3called nohle metals? I have been interested in that question for a long time. Having been a farmer in my earlier life, 1 found posts in the ground did not decay as much in the ground as above the ground and you find that the case where you have the gold fillings and the copper or zinc fillings adjacent,--where below the gum or above the gum may have a similar effect.

Dr. Carter.-Mr. Chairman and Gentlemen: I came in almost too late to hear enough of this paper to discuss it, but relative to whether or not it is best to use noble metals 
or some metals containing copper and zinc, I believe a great deal of the decay going on in the mouth is not entirely due to the metals that we use but is probably due to a lack of prophylactic measures many times. I believe we sometimes put bands on teeth and send the patients out and tell them to return in a month. It appears to me that it would not make a lot of difference whether platinum or gold or base metal appliances were used, there would be a great liability of decay under such circumstances. Although there may be some merits in the base metal in appliances, I think much of our trouble could be eradicated by better attention to prophylaxis in many cases.

Dr. $M c$ Coy.-I will not consume any time in closing the discussion. I was sorry not to be able to place this paper in Dr. Cavanagh's hands prior to the meeting, as it placed him at a disadvantage, but in rush of preparation for this meeting my address was not completed in time to get it to him.

I am much pleased to think my remarks have evoked as much discussion as they have, and I trust that even though we may not have settled anything definitely we may feel stimulated to-direct our energies along the disputed lines and eventually do our share in their settlement.

\title{
THE QUESTION OF A UNIVERSAL APPLIANCE*
}

\author{
By Harry P. Beaser, D.D.S., Fresno, Calif.
}

$\mathrm{A}^{\mathrm{T}}$ $T$ the time the healing art became recognized as such and was separated from the barber trade, the search for a panacea for all ills began. As time progressed, the different departments of the "Profession of Medicine," as it was now called, began to divide into specialties, and the search has continued, the searchers declaring from time to time that the wonderful discovery has been made, and therefore the troubles from that particular thing are at an end forever. The statement that the drug, the apparatus, the appliance, or the process system was ail that any one need have to accomplish the perfect result has often been heralded, but has always proved false.

As this was true in times past, it is equally true at the present for one need only to pick up a magazine, technical or otherwise, to read the announcement of some one claiming that he has. at last discovered the necessary thing to fill all the requirements in the treatment of this or that, and it is further stated that it is so simple that most any one can use it. All you have to do is to get the original article, usually patented, from the inventor or his agent, and the result will follow without any further attention from the operator.

As we are naturally a mechanically inclined race of people, and dentistry being largely a mechanical science, it follows that a great deal of attention is directed toward dentistry by the panacea searcher, and the science of orthodontia, being carried on practically altogether by mechanical means, receives a full share of attention.

There is no doubt but that most inventors of systems and universal appliances are absolutely sincere in their statements regarding the uses of their inventions, but their enthusiasm over their discoveries leads the unsuspecting and undereducated person to believe that all that is required is to adjust the appliance to any case, turn the crank, and grind out the result.

\footnotetext{
*Read before the Alumni Society of the Dewey School of Orthodontia, Chicago, Ill., March 13, 14,15 , and 16,1917 .
} 